\title{
Knowledge and attitudes of patients with diabetes mellitus in a primary health care system
}

\author{
CONHECIMENTOEATITUDEDEUSUÁRIOSCOMDIABETESMELLITUSEMUMSERVIÇODE \\ ATENÇÃO BÁSICA À SAÚDE
}

\section{CONOCIMIENTO YACTITUD DE PACIENTES CON DIABETES MELLITUS EN UN SERVICIO DE ATENCIÓN BÁSICA DE SALUD}

\section{Kelli Cristina Silva de Oliveira' ${ }^{1}$ Maria Lúcia Zanetti ${ }^{2}$}

\begin{abstract}
The objective of this study was to characterize patients with type 2 diabetes mellitus, according to sociodemographic and clinical variables, and to analyze scores of knowledge and attitudes regarding the disease. Participants were 79 users who received care in a primary health care service, in 2008. The Diabetes Mellitus Knowledge (DKN-A) and Attitude (ATT-19) questionnaires were used for data collection. The population was formed by adults and elderly adults, who were between 30 and 80 years old. Most were literate (96.3\%); married (63.3\%); female (63.3\%) and classified as class-2 obesity. As to the knowledge about the disease, subjects obtained scores lower than 8, indicating unsatisfactory results on self-care. Scores obtained regarding attitudes show difficulties to cope with the disease. Results evidence the need to adopt a Diabetes Education Program at the studied unit.
\end{abstract}

\section{DESCRIPTORS}

Diabetes mellitus

Primary Health Care

Attitude to health

Knowledge

Nursing

\section{RESUMO}

Este estudo teve como objetivos caracterizar os usuários com diabetes mellitus tipo 2 , segundo variáveis sócio-demográficas e clínicas, e analisar os escores de conhecimento e atitude em relação à doença. Participaram 79 usuários atendidos em um serviço de atenção básica à saúde em 2008. Para a obtenção dos dados, foram utilizados os Questionários de Conhecimento (DKN - A), e de Atitudes Psicológicas do Diabetes (ATT - 19). A população caracterizou-se por adultos e idosos, com idade entre 30 e 80 anos; predominantemente do sexo feminino $(63,3 \%)$, casada $(63,3 \%)$ e alfabetizada $(96,3 \%)$ com obesidade classe II. Quanto ao conhecimento da doença, obtiveram-se escores inferiores a oito, indicando resultado insatisfatório quanto ao autocuidado. Os escores obtidos em relação às atitudes mostram dificuldades para o enfrentamento da doença, apontando os resultados para a necessidade de implantação de Programa de Educação em Diabetes a Unidade de Estudo.

\author{
DESCRITORES \\ Diabetes mellitus \\ Atenção Primária à Saúde \\ Atitude frente a saúde \\ Conhecimento \\ Enfermagem
}

\begin{abstract}
RESUMEN
Este estudio objetivó caracterizar a pacientes de diabetes mellitus tipo 2 , según variables sociodemográficas y clínicas, y analizar los puntajes de conocimiento $y$ actitud relativos a la enfermedad. Participaron 79 pacientes atendidos en servicio de atención básica de salud, en 2008. Para la obtención de datos se utilizaron el Cuestionario de Conocimientos (DKN-A) y de Actitudes Psicológicas de la Diabetes (ATT-19). La población abundó en adultos y ancianos con edad entre 30 y 80 años, predominando sexo femenino $(63,3 \%)$, casados $(63,3 \%)$ y alfabetizados $(96,3 \%)$, con obesidad grado II. Respecto al conocimiento de la enfermedad, se obtuvieron puntajes inferiores a ocho, indicando resultado insatisfactorio referido al autocuidado. Los puntajes relativos a actitudes muestran dificultad para enfrentar la enfermedad. Los resultados determinan la necesidad de implantación de un Programa de Educación en Diabetes a Unidad de estudio.
\end{abstract}

\author{
DESCRIPTORES \\ Diabetes mellitus \\ Atención Primaria de Salud \\ Actitud frente a la salud \\ Conocimiento \\ Enfermería
}

\footnotetext{
${ }^{1}$ Registered Nurse. PhD in Nursing from the Post-Graduate Fundamental Nursing Program of the School of Nursing of Ribeirão Preto, University of Sao Paulo. Ribeirao Preto, SP, Brazil. kellicsilva@usp.br ${ }^{2}$ Associate Professor of the School of Nursing of Ribeirão Preto, University of Sao Paulo. Ribeirao Preto, SP, Brazil. zanetti@eerp.usp.br
} 


\section{INTRODUCTION}

A chronic disease for most people can modify their lives in profound ways. The changes are related to activities of quotidian life, since, from the establishment of the diagnosis, feelings of anguish and despair occur when faced with the perception of low control over their life, diminishing the power to act and think. This situation leads people to the need for integral healthcare, involving biological, cultural, social, economic, and psychological aspects, among others. In this context, patients with diabetes mellitus, in particular, need systematic monitoring by a multidisciplinary healthcare team providing the tools necessary to manage the disease with a view to self-care. These tools are related to information that enables the user to cope, on a daily basis, with situations resulting from the disease, such as acceptance, taking decisions faced with episodes of hypoglycemia and hyperglycemia, the caloric value of foods, the correct use of prescribed medications, the monitoring of capillary blood glucose in the domicile, and the comorbidities, such as arterial hypertension.

The difficulties faced on a daily basis by users with diabetes mellitus, led us to investigate what knowledge they have regarding the disease and their readiness to face the challenges for its control, which constituted the aim of this investigation.

\section{OBJECTIVES}

The objectives of this study were to characterize the type 2 diabetes mellitus patients of a Primary Health Unit of Ribeirão Preto, Sao Paulo, concerning sociodemographic and clinical variables; and to analyze the scores of knowledge and attitude regarding the disease.

\section{LITERATURE REVIEW}

Self-care education is a fundamental aspect of the treatment of people with diabetes mellitus and its importance is acknowledged in several studies conducted in communities with different socioeconomic and cultural characteristics ${ }^{(1)}$. For effective diabetes education training, knowledge, pedagogical skills, communication and listening skills, comprehension and negotiation skills are required by the multidisciplinary healthcare team ${ }^{(2)}$.

When considering the complexity of the treatment and the associated comorbidities, health managers and professionals have sought to establish structured education and intervention programs so that the user with diabetes mellitus can achieve and maintain the quality of life. Diabetes education has constituted the basis for the management and control of the disease ${ }^{(3)}$. The need to develop teaching activities and educational practices of health, directed at the person with diabetes mellitus and their family, centered on the availability of knowledge and attitude toward the disease, is related to the prevention of complications through self-management of the disease, which allows the person to better exist with their condition ${ }^{(4)}$.

Education for self-management is the process of teaching the user to manage their disease. The goals of diabetes education are to improve metabolic control, to prevent acute and chronic complications, and to improve quality of life at reasonable costs. However, there is a significant deficit of knowledge and skill in 50 to $80 \%$ of individuals affected by this disease ${ }^{(5)}$. During the educational process, the user must, in conjunction with the multidisciplinary healthcare team, seek effective strategies that help to manage the disease. This is the most important long-term investment that society can offer, since the health costs of the individuals, triggered by the complications of the disease are enormous ${ }^{(6)}$.

Health programs, overall, are offered with the aim of reducing the number of diseases and their complications, preventing premature deaths. They include educational interventions designed to provide information and skills to the individual, in the case of diabetes mellitus, to achieve good metabolic control from the comprehension of the disease and the treatment management. The information offered during the educational interventions promotes the search for behavior change, which, consequently, will make a difference in the treatment of disease ${ }^{(7)}$. Health professionals should involve people with diabetes mellitus in all phases of the educational process, therefore, to assume the responsibility of the therapeutic role, the user must master knowledge and develop skills that they can instrumentalize for self-care. To do so, it needs to be clear regarding what is needed, valued and what they want to obtain in their lives ${ }^{(8)}$. Thus, it is the responsibility of the multidisciplinary team, in addition to making available to the user all the necessary information about their disease, to accompany them for a period of time in order to assist them in making decisions, facing the many situations that the disease imposes. Thus, the evaluation of the knowledge and attitudes related to the health of people affected, will provide support to comprehend the difficulties inherent in managing the disease and, consequently, improving metabolic control. Health professionals, particularly nurses, should develop skills and tools that guide the nursing interventions for users with type 2 diabetes mellitus at the levels of primary, secondary and tertiary healthcare. 


\section{METHOD}

This was a cross-sectional study in a Primary Health Unit (PHU) in the municipality of Ribeirao Preto, Brazil. This unit was chosen for its catchment area and number of patients with type 2 diabetes mellitus. The sample consisted of 79 users with type 2 diabetes mellitus, registered in the Registration and Monitoring System for Hypertensive and Diabetic Patients - Hiperdia. A systemized script was constructed considering the sociodemographic variables: gender, age, schooling, marital status, occupation, family income, and clinics: diagnostic and treatment. For the collect of data on knowledge and attitude the Portuguese versions of the questionnaires Knowledge - DKN - A and the Diabetes Psychological Attitudes Questionnaire - ATT - 19 were used. These questionnaires were translated into Portuguese and validated in Brazil( ${ }^{(9)}$. In the reliability analysis, test-retest, of the instruments Kappa coefficients were found ranging from 0.56 to 0.69 for the DKN-A and 0.45 to 0.60 for ATT 19. It is worth mentioning that these instruments are easily comprehended by individuals, reliable and valid for use in the evaluation of people with diabetes mellitus.

The DKN - A is a self-administered questionnaire containing 15 items of multiple choice answers regarding different aspects related to the general knowledge of diabetes mellitus. It presents five broad categories: basic physiology, including the action of insulin; hypoglycemia; food groups and their substitutes; management of diabetes in the intercurrence of any other disease; and general care principles of the disease. The measurement scale used was of 0 to 15 , where a score of one (1) is attributed for a correct answer and a score of zero (0) for an incorrect answer. Items 1 to 12 require a single correct answer. For items 13 to 15 two answers are correct and both should be checked to obtain a score of one (1). A score greater than eight indicates knowledge about diabetes mellitus.

The ATT - 19 is a self-administered instrument to measure the psychological adjustment to diabetes mellitus, developed in response to the need to evaluate the psychological and emotional aspects regarding the disease. It consists of nineteen items that include six factors: a) stress associated with diabetes, b) receptivity to the treatment, c) confidence in the treatment, d) personal efficacy, e) perception of health, f) social acceptance. Questions 11,15 and 18 start with reverse scores. The main application of the ATT - 19 is associated with the evaluation of the educational intervention. Each response is measured by a five-point Likert type scale (I strongly disagree - score 1 ; to I completely agree - score 5). The total value of the scores varies between 19 and 95 points. A score above 70 points indicates a positive attitude regarding the disease.

To obtain data on sociodemographic and clinical variables related to the knowledge and attitude, face to face interviews were used, lasting 50 minutes. The researcher initially conducted a survey of users with type 2 diabetes mellitus enrolled in the Registration and Monitoring System for Hypertensive and Diabetic Patients - Hiperdia for the recruitment of the study population. Based on this information, the researcher invited the users to participate in the research, clarified the nature of the study and its objectives and, after the user signed the Terms of Free Prior Informed Consent, began the interview. The interviews were conducted individually in a room with closed doors, while respecting the privacy of the user and providing an organized and calm environment, favoring the concentration of the subject for the emission and recording of the responses to the instruments. The responses were recorded by the researcher on the questionnaire itself, concomitant with the performance of the interview, due to the difficulty of understanding of the users.

The data obtained were entered into the database previously designed using the Excel version 2007 program, applying the technique of double entry in order to verify possible transcription errors. For analysis, the data was transposed into the SPSS 14.0 program. Regarding the presentation of the results, descriptive statistics were used. The project was approved by the Ethics Committee of the School of Nursing of Ribeirao Preto, University of Sao Paulo, Brazil, and by the Health Secretariat of Ribeirao Preto, protocol number 0925/2008. The use of the instruments - the Knowledge questionnaire - DKN - A and the Diabetes Psychological Attitudes Questionnaire - ATT - 19, was authorized by the authors through electronic means.

\section{RESULTS}

Of the $79(100 \%)$ users investigated, ages ranged between 30 and 80 years, mean $64.46 \pm 11.15$. The majority were in the age group $60-80$ years; were predominantly female (63.3\%). Most were married (63.3\%) and illiterate (96.3\%). In terms of occupation it was found that, 33/79 (41.8\%) were housewives and $21 / 79$ (26.6\%) retirees, with monthly incomes of between one and five minimum wages. In relation to the body mass index, 33/79 (41.8\%) were overweight, $23 / 79$ (29.1\%) had class I obesity and $13 / 79(16.5 \%)$ class II obesity. Waist circumference ranged from 60 to $140 \mathrm{~cm}$, mean $107.06 \pm 15.29 \mathrm{~cm}$. The systolic blood pressure values ranged from 100 to $180 \mathrm{mmHg}$, mean $133.87 \pm 17.54 \mathrm{mmHg}$ and diastolic blood pressure values were of 60 to $140 \mathrm{mmHg}$, mean $80 \pm 10.50 \mathrm{mmHg}$. Most users had less than 10 years of evolution of the disease, and $96.3 \%$ made use of medication.

Figure 1 shows the dispersion of the scores obtained in relation to the knowledge of the patients with type 2 diabetes mellitus, with the application of the DKN-A questionnaire. Most participants, 51/79 (64.6\%), obtained scores less than or equal to eight and $28 / 79$ (35.4\%) higher than 8 in relation to knowledge about diabetes mellitus, indicating unsatisfactory results for the comprehension regarding self-care for the disease. 


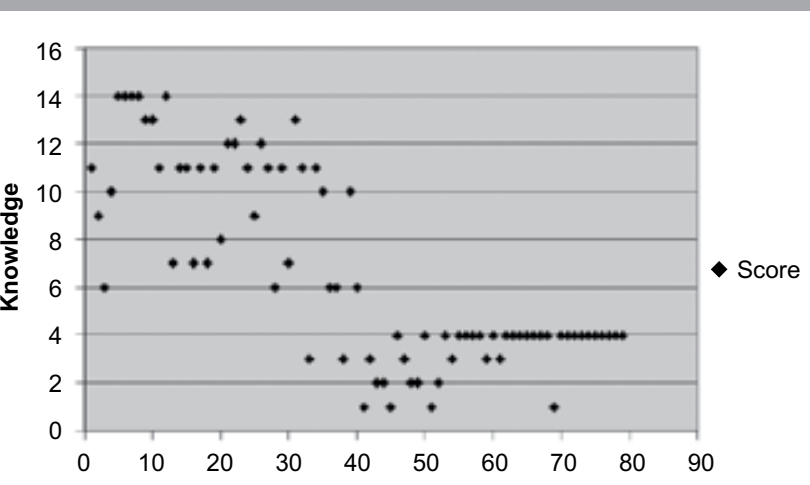

Users with type 2 diabetes mellitus

Figure 1 - Scores obtained by the patients with type 2 diabetes mellitus, enrolled in the Dr. Nelson Barrionovo Primary Health Unit, Ribeirão Preto, SP, with the DKN-A questionnaire regarding knowledge of the disease

Figure 2 shows the dispersion of scores obtained in relation to the coping attitudes displayed by the users with diabetes mellitus, when applying the ATT-19 questionnaire. These ranged from 35 to 80 points of the ATT- 19 . The minimum score is 19 points and the maximum 95 points. Scores above 70 indicate a positive attitude toward the disease. Regarding the attitude scores, it was found that $74 / 79(93.7 \%)$ of the participants had scores less than or equal to 70 , indicating low readiness for learning about the disease. It is highlighted that only $5 / 79$ (6.3\%) of the participants scored over 70 points.

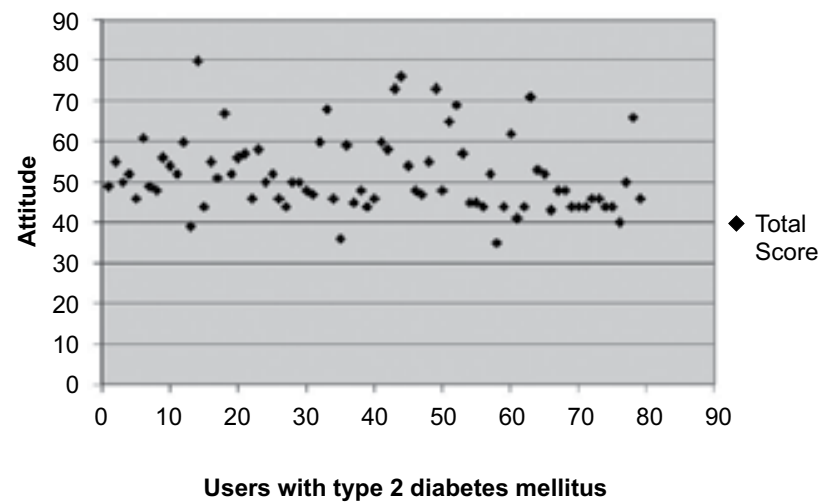

Figure 2 - Scores obtained by the users with type 2 diabetes mellitus, enrolled in the Dr. Nelson Barrionovo Primary Health Unit, Ribeirao Preto, SP, with the ATT-19 questionnaire regarding attitudes to coping with the disease

\section{DISCUSSION}

Of the 79 subjects investigated, the median was 65 years of age, confirming the study population as adults and elderly users. A multicenter study on the prevalence of diabetes mellitus in Brazil showed that its frequency increased gradually after 50 years of life. This study also highlighted the importance of this disease as a Public
Health problem, relating the progressive trend of aging of the population ${ }^{(10)}$. Regarding gender, in this study there was a predominance of females. The characteristics of the subjects in relation to gender and age maintained characteristics similar to those described in nonrandomized studies which showed a prevalence in females ${ }^{(11)}$.

When considering that most of the subjects investigated were aged over 65 years, it is necessary to reinforce the importance of developing an educational program with an adult learning strategy. With regard to marital status, it was found that the majority were married (63.3\%), and regarding the occupation, $33 / 79$ (41.8\%) were housewives and $21 / 79(26,6 \%)$ retired, in concordance with another study ${ }^{(12)}$. In relation to schooling, the subjects presented low levels of education, 59\%, with up to eight years of study, in agreement with other studies performed in Ribeirao Preto, $\mathrm{SP}^{(8-13)}$. Concerning family income, most people received up to five minimum wages, similar to that found in other studies ${ }^{(8-13)}$. Regarding the body mass index it was found that the BMI was 22.07 to $45.52 \mathrm{~kg} /$ $\mathrm{m}^{2}$, mean $30,50 \pm 5 \mathrm{~kg} / \mathrm{m}^{2}$. These findings show that the subjects were overweight or obese. It is estimated that $80 \%$ of users with type 2 diabetes mellitus are obese or overweight $^{(14)}$. The waist circumference ranged from 60 to $140 \mathrm{~cm}$, mean $107.06 \pm 15.29 \mathrm{~cm}$. The mean waist circumference found in this study, is above the parameters set by the WHO, which recommends values of waist circumference of $90 \mathrm{~cm}$ for men and $85 \mathrm{~cm}$ for women ${ }^{(15)}$.

The systolic arterial pressure values ranged from 100 to $180 \mathrm{mmHg}$, mean $133.87 \pm 17.54 \mathrm{mmHg}$ and the diastolic blood pressure values were of 60 to $140 \mathrm{mmHg}$, mean $80 \pm 10.50 \mathrm{mmHg}$. A study performed in Brazil, which investigated the cardiovascular risk factors, related to physical activity and/or nutrition of patients with arterial hypertension, showed that changes in lifestyle, combined with healthy eating habits and the regular practice of physical exercise are important aspects which constitute important aspects to be considered in the interventions aimed at controlling this disease ${ }^{(16)}$. Therefore, arterial hypertension is often associated with other cardiovascular risk factors and metabolically associated with dyslipidemia, glucose intolerance, central obesity and an elevated body mass index.

Regarding the length of disease evolution, 54 (68.4\%) of the subjects had less than 10 years. Studies have shown that, in most cases, the diagnosis of type 2 diabetes mellitus is carried out late and that there is an under-diagnosis of this disease. In most cases, when it is diagnosed, the patient already presents some form of complication ${ }^{(10-17)}$. By comparing the data from this study, a higher prevalence was observed of individuals who used oral antidiabetics of the sulfonylurea therapeutic class and used insulin and a lower prevalence of individuals using combined thera$\mathrm{py}^{(18)}$. In the present study, one of the difficulties encountered for achieving the goals of good blood pressure control, BMI and waist circumference, refers to the difficulty 
of adherence to the treatment. Treatment adherence is the biggest challenge for the multidisciplinary team in the care of the user with type 2 diabetes mellitus. Treatment adherence has implications in the compliance with the dietary plan, the performance of physical activity, the taking of the medications prescribed, at the times indicated and in the right doses, in addition to attending the medical consultations, the realization of laboratory examinations and the participation in the Registration and Monitoring System for Hypertensive and Diabetic Patients - Hiperdia. To change this scenario, it is necessary that the multidisciplinary team, particularly nurses, adopt strategies aimed at identifying the individual risk such as the recognition of variables that could interfere in the therapeutic adherence of the users attended in the Units.

Regarding the knowledge of the users with type 2 diabetes mellitus when the questionnaire DKN-A was applied, most participants, 51/79 (64.6\%), obtained scores less than or equal to eight and 28/79 (35.4\%) higher than 8 in relation to knowledge about diabetes mellitus, indicating unsatisfactory results for the comprehension regarding self-care for the disease. It is recognized that scientific knowledge about diabetes mellitus is a relevant resource to guide the multidisciplinary team in making clinical decisions for treating the disease and also to prepare them to educate the users in the knowledge and adherence to self-care. A study conducted in a city of the State of Sao Paulo, with 54 patients with diabetes mellitus monitored for 12 months in a diabetes education program showed a significant increase of knowledge with emphasis on the general topics related to the concept, pathophysiology and treatment of the disease ${ }^{(19)}$. Thus, the importance of the offer of educational strategies in the health services for acquiring knowledge can be perceived. In this aspect, the Protocol of Hypertension and Diabetes Care of the Health Secretariat of Ribeirao Preto, SP, describes an Educational Program in Hypertension and Diabetes as a model for use in the Health Units for users with diabetes mellitus and arterial hypertension. This program contains topics to be addressed by the multidisciplinary healthcare team, such as the definition of diabetes and hypertension, physical activity, nutritional needs and how to plan the diet, among other things ${ }^{(20)}$. It seems, however, that the Unit under study does not offer a systematic Program of education in diabetes and hypertension to the users registered there, as recommended in the Protocol. This situation may partly explain the scores obtained regarding the knowledge about the disease. Therefore, the implementation of the Protocol for Hypertension and Diabetes Care in the Unit could minimize the lack of knowledge of the users, and contribute to improved metabolic control.

In relation to the scores obtained using the Diabetes Psychological Attitudes Questionnaire ATT - 19, it was found that most subjects presented scores below 70 points, which indicates that they have not yet achieved a positive attitude towards the modifications in the life style expected in or- der to obtain good metabolic control. Conversely, it is necessary to consider that knowledge does not always lead to attitude change in the user faced with the daily demands that the treatment imposes in the quotidian. A study that compared the attitudes of patients with type 2 diabetes mellitus with those of health professionals regarding the management of the disease showed that the attitude and opinion of the users are determinant criteria for its care and control. Thus, the attitude toward diabetes mellitus presents an intimate relationship with the behavior adopted by the health professional in the care ${ }^{(21)}$.

The educational programs in type 2 diabetes mellitus should be based on a dialogical posture and on the exchange of knowledge, promoting the interchange between scientific and popular knowledge, being that both professionals and patients have much to teach and learn. The multidisciplinary team should recognize the need to update and seek innovative strategies to care for adult clients and to develop communication skills which include listening, negotiation, confidence in the treatment, personal efficacy, health perception, social acceptance and empathy for the establishment of a bond with the people with type 2 diabetes mellitus.

For users with low self-efficacy, strategies aiming to change that perception must be implemented with a view to better emotional, physical and social adjustment ${ }^{(22)}$. In this aspect, the nurses could assume the role within the multidisciplinary healthcare team of articulators of the educational process, encouraging the users with diabetes mellitus to take their own decisions regarding the disease, the treatment, and the physical and emotional aspects, considering the proximity and the time spent during a nursing consultation.

\section{CONCLUSION}

It was concluded that, regarding the knowledge of the disease, the users presented scores lower than eight, indicating unsatisfactory results concerning self-care and the scores obtained in relation to attitude showed difficulties for coping with the disease. These results highlight the following recommendations: the immediate implementation of the Diabetes Education Program proposed in the Protocol of Diabetes and Hypertension Care; the effective participation of nurses in nursing consultations, according to attributions and competences described in the Protocol of Diabetes and Hypertension Care; the maintenance of the Registration and Monitoring System for Hypertensive and Diabetic Patients - Hiperdia, updated, in order to ensure the medicines and supplies to users and ongoing training to the professionals working in the Unit of study aimed at producing quality healthcare. The difficulty for the users to give responses due to low levels of education, and the lack of national literature for data comparison constituted limitations of the study. Thus, there is a need for development of other studies in Brazil for future comparisons. 
It is recommended that health professionals, particularly nurses reinforce the importance of registration of the users with diabetes mellitus in the Hiperdia system, and use this space of care for diabetes education in order to

\section{REFERENCES}

1. Sousa VD, Zauszniewski JA. Toward a theory of diabetes selfcare management. J Theory Constr Test. 2005;9(2):61-7.

2. Rotter DL, Hall JA, Merisca R, Nordstrom B, Cretin D, Svarstad $B$. Effectiveness of interventions to improve patient compliance: a meta analysis. Med Care. 1998;36(8):1138-61.

3. Liao D, Asberry PJ, Shofer JB. Improvement of BMI, body composition, and body fat distribution with lifestyle modification in Japonese Americans with impaired glicose tolerance. Diabetes Care. 2002;25(9):1504-10.

4. Funnell MM, Brown TL, Childs BP, Haas LB, Hosey GM, Jensen $B$, et al. National standards for diabetes self-management education. Diabetes Care. 2008;31 Suppl 1:S97-104.

5. Clement S. Diabetes self-management education. Diabetes Care. 1995;18(8):1204-14

6. Torres HC. Avaliação de um programa educativo em diabetes mellitus com indivíduos portadores de diabetes tipo 2 em Belo Horizonte, MG [tese doutorado]. Rio de Janeiro: Escola Nacional de Saúde Pública Sergio Arouca, Fundação Oswaldo Cruz; 2004.

7. Franz MJ, Warshaw H, Daly AE, Green-Pastors J, Arnold MS, Bantle J. Evolution of diabetes medical nutrition therapy. Postgrad Med J. 2003;79(927):30-3.

8. Rocha RM, Zanetti ML, Santos MA. Comportamento e conhecimento: fundamentos para prevenção do pé diabético. Acta Paul Enferm. 2009;22(1):17-23.

9. Torres HC, Hortale VA, Schall VT. Validação dos questionários de conhecimento (DKN-A) e atitude (ATT-19) de Diabetes Melittus. Rev Saúde Pública. 2005;39(6):906-11.

10. Malerbi DA, Franco LJ; The Brazilian Cooperative Group on the Study of Diabetes Prevalence. Multicenter study of the prevalence of diabetes mellitus and impaired glucose tolerance in the urban Brazilian population aged 30-69 yr. Diabetes Care. 1992;15(11):1509-16.

11. Teixeira CRS, Zanetti ML. Custos de consultas médicas em pessoas com diabetes mellitus durante um programa educativo. Rev Baiana Saúde Pública. 2006;30(2):261-71.

12. Otero LM, Zanetti ML, Teixeira CRS. Características sócio demográficas e clínicas de portadores de diabetes em um serviço de atenção básica à saúde. Rev Latino Am Enferm. 2007;15(n.esp):768-73. minimize the difficulties encountered in relation to the knowledge and attitude of the users for the adequate day to day management of the disease.

13. Gimenes HT, Zanetti ML, Haas VJ. Factors related to patient adherence to antidiabetic drug therapy. Rev Latino Am Enferm. 2009;17(1):46-51

14. Feldstein AC, Nichols GA, Smith DH, Stevens VJ, Bachman $K$, Rosales $A G$, et al. Weight change in diabetes and glycemic and blood pressure control. Diabetes Care. 2008;31(10):1960-5.

15. Sociedade Brasileira de Diabetes (SBD). Tratamento e acompanhamento do diabetes mellitus: diretrizes da Sociedade Brasileira de Diabetes. São Paulo: SBD; 2007.

16. Piovesana PM, Colombro RCR, Gallani MCB J. Hypertensive patients and risk factors related to physical activity and nutricion. Rev Gaúcha Enferm. 2006;27(4):655-7.

17. Torquato MTCG, Montenegro RM, Viana LAL, Souza RAHG, Lanna JCB, Durin CB, et al. Prevalência do diabetes mellitus, diminuição da tolerância à glicose e fatores de risco cardiovascular em uma população urbana adulta de Ribeirão Preto. Diabetes Clin. 2001;5(3):183-9.

18. Dailey G, Kim MS, Lian JF. Patient compliance and persistence with antihyperglycemic drug regimens: evaluantion of a medicaid patient population with type 2 diabetes mellitus. Clin Ther. 2001;23(8):1311-20.

19. Otero LM, Zanetti ML, Ogrizio MD. Conhecimento do paciente diabético acerca de sua doença, antes e depois da implementação de um programa de educação em diabetes. Rev Latino Am Enferm. 2008;16(2):231-7.

20. Ribeirão Preto. Secretaria Municipal da Saúde. Protocolo de atendimento em hipertensão e diabetes [Internet]. Ribeirão Preto; 2006 [citado 2009 jun. 16]. Disponível em: http://www. ribeiraopreto.sp.gov.br/ssaude/programas/cronico/prot-hipertensao.pdf

21. Clark M, Hampson SE. Comparison of patients' and healthcare professionals' beliefs about and attitudes towards type 2 diabetes. Diabetes Med. 2003;20(2):152-4.

22. Salvetti MG, Pimenta CAM. Dor crônica e a crença de autoeficácia. Rev Esc Enferm USP. 2007;41(1):135-40. 